\title{
Identification of quercetin from fruits to immediately fight Zika
}

\author{
Amrita Roy, Liangzhong Lim and Jianxing Song* \\ Department of Biological Sciences, Faculty of Science, National University of Singapore; 10 Kent \\ Ridge Crescent, Singapore 119260
}

Short title: Quercetin inhibits Zika NS2B-NS3 protease

*: corresponding author, $\underline{\text { dbssjx @ nus.edu.sg. }}$

The authors have declared that no competing interests exist.

Key words: Zika virus; Dengue virus; NS2B-NS3 protease; Enzymatic kinetics; Quercetin; Flavonoid. 


\section{Abstract}

Zika virus is spread mainly by the bite of an infected mosquito, which can be passed from a pregnant woman to her fetus, thus leading to birth defects including more than microcephaly. It has been recently estimated that one-third of the world population will be infected by Zika in the near future, but unfortunately so far there is no vaccine or medicine for Zika. In particular, the special concern on the vaccine treatment to Zika and Dengue arising from antibody-dependent enhancement strongly emphasizes the key role of its NS2B-NS3 protease (NS2B-NS3pro) as a target for antiZika drug discovery/design due to its absolutely-essential role in viral replication.

In response to the current global health emergency triggered by the Zika outbreak, we successfully obtained several active forms of Zika NS2B-NS3pro and further attempted to discover its inhibitors from eatable plants and traditional herbal medicines to immediately fight Zika. Here, for the first time, we discovered that quercetin, a flavonoid extensively existing in many fruits and vegetables, effectively inhibits Zika NS2B-NS3pro. We further quantify its inhibitory activity with $\mathrm{IC}_{50}$ of 26.0 $\pm 0.1 \mu \mathrm{M}$; and $K_{\mathrm{i}}$ of $23.0 \pm 1.3 \mu \mathrm{M}$. As quercetin has been extensively found in fruits, vegetables, leaves and grains, our discovery would benefit the public to immediately fight Zika.

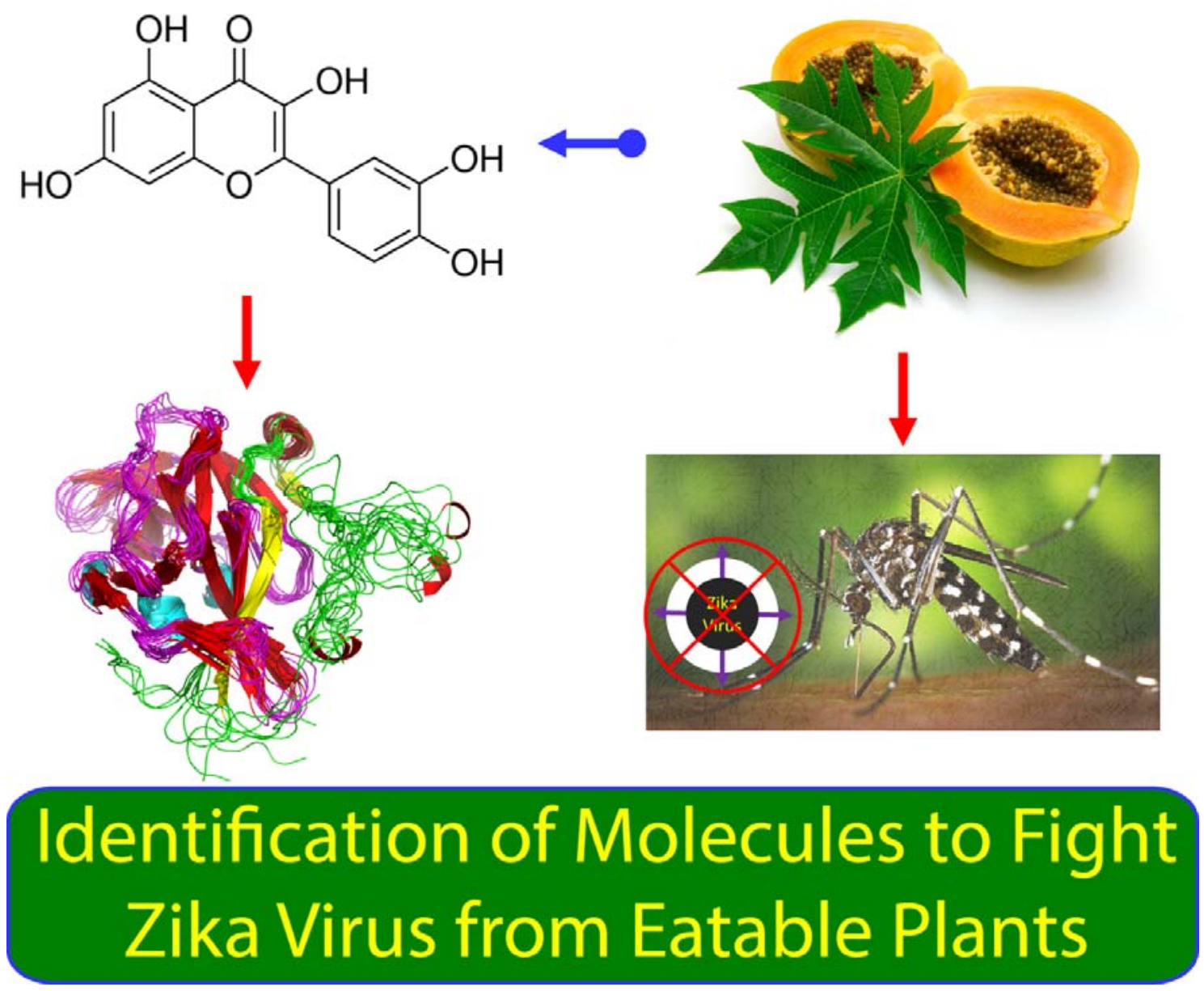




\section{Introduction}

Zika virus was originally isolated from a sentinel rhesus monkey in the Zika Forest of Uganda in 1947 (1), which is transmitted to humans by Aedes species mosquitoes. Since 2007, large epidemics of Asian genotype Zika virus have been reported around the world (24). Recently it has been estimated that one-third of the world population will be infected in the near future (5). Most seriously, Zika infection has been found to be associated with serious sequelae such as Guillain-Barré syndrome, and microcephaly in newborn infants of mothers infected with Zika virus during pregnancy (6-9), and consequently WHO has declared a public health emergency for Zika virus (10). Zika virus represents a significant challenge to the public health of the whole world but unfortunately there is no effective vaccine or other therapy available so far.

Zika virus with a single stranded, positive sense RNA genome of $10.7 \mathrm{~kb}$ belongs to the flavivirus genus, which also contains Dengue, yellow fever, West Nile, Japanese encephalitis, and tick-borne encephalitis viruses $(4,11)$. Zika virus shares a high degree of sequence and structural homology with other flaviviruses particularly Dengue virus, thus resulting in immunological cross-reactivity (7). As such, Zika was proposed as the fifth member of the Dengue serocomplex. Seriously, the current Zika outbreaks are largely localized within dengue-endemic areas, it is thus possible that preexisting dengue-induced antibodies may enhance Zika infection by antibody-dependent enhancement (ADE), a factor that makes the vaccine approaches extremely challenging (7).

Zika genome is translated into a single $\sim 3,500$-residue polyprotein, which is further cleaved into 3 structural proteins and 7 non-structural proteins (11). The correct processing of the polyprotein is essential for replication of all flaviviruses, which requires both host proteases and a viral NS2B-NS3 protease (NS2B-NS3pro) (11-18). As a consequence, the flaviviral NS2B-NS3pro has been well-established to be key targets for developing antiviral 
drugs (11-18). In particular, the unique concern on the vaccine treatment to Zika and Dengue strongly emphasizes the irreplaceable role of the Zika protease as a target for antiviral drug discovery/design.

As facilitated by our previous studies on Dengue NS2B-NS3pro (12), we started to work on Zika NS2B-NS3pro immediately after the outbreak of Zika and now successfully obtained several active forms of recombinant Zika NS2B-NS3pro. Furthermore, we attempted to discover its inhibitors from eatable plants and traditional herbal medicines to fight Zika with no delay. Here we release the result that quercetin, a flavonoid existing in many fruits and vegetables, inhibits Zika NS2B-NS3pro, and subsequently determined its inhibitory activity. For the first time, our study reveals that many fruits, vegetables, leaves and grains, as well as herbals containing quercetin are expected to have anti-Zika activity, and therefor can join in to combat Zika immediately. 


\section{Results and discussion}

\section{Cloning, expression and purification of the active Zika NS2B-NS3pro.}

Based on the sequence alignment with NS2B and NS3pro of the Dengue serotype 2 we previously studied (12), the corresponding Zika sequences were identified for the NS2B and NS3pro of the Asian Zika virus. From synthetic genes with E. coli preferred codons, we amplified and subsequently cloned the DNA fragments into His-tagged expression vectors. The recombinant proteins were expressed in BL 21 cells and then purified by $\mathrm{Ni}^{2+}$-affinity chromatography, followed by further purification with FPLC gel-filtration chromatography. Recombinant protease samples were checked by SDS-PAGE, molecular weights verification with ESI-MS and protein sequencing with time-of-flight-mass spectrometer (Applied Biosystems). Protein concentration was determined by the UV spectroscopic method with 8 M urea (19).

All enzymatic/inhibitory experiments were performed in $50 \mathrm{mM}$ Tris- $\mathrm{HCl}$ at $\mathrm{pH} 8.5$, with a Cary Eclipse fluorescence spectrophotometer in triplicate and data are presented as mean \pm SD. The Zika NS2B-NS3pro we obtained is fully active as judged from its enzymatic activity on a fluorescent substrate Bz-nKRR-AMC (12).

\section{Identification of quercetin as an inhibitor}

Quercetin purchased from Sigma-Aldrich (Fig 1A) is a flavonoid extensively existing in many fruits, vegetables, leaves and grains such as Carica papaya (Fig 1B). When Zika NS2B-NS3pro at $50 \mathrm{nM}$ (Fig 1C) was pre-incubated with quercetin at different concentrations, the enzymatic activity was inhibited at a dose-dependent manner (Fig 2A), indicating that quercetin is an inhibitor of Zika NS2B-NS3pro. 
<smiles>O=c1c(O)c(-c2ccc(O)c(O)c2)oc2cc(O)cc(O)c12</smiles>

\section{Quercetin}

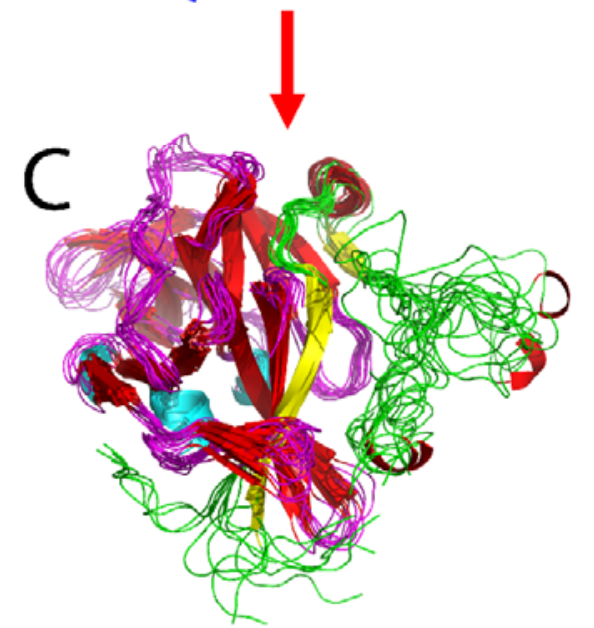

\section{Zika NS2B-NS3pro}
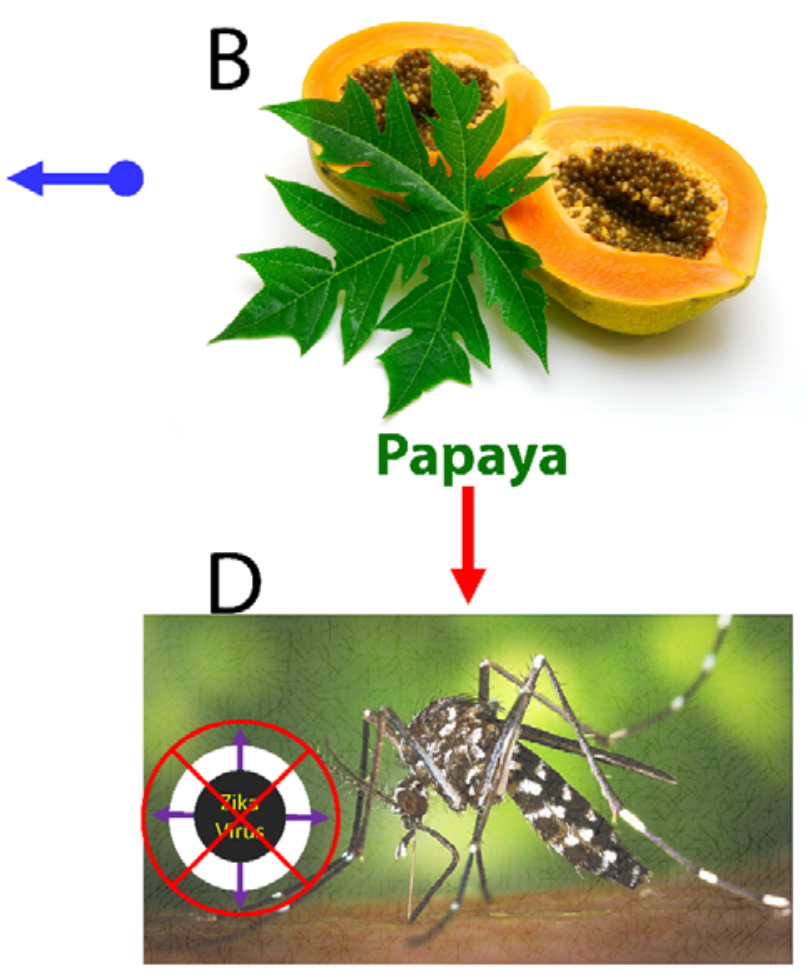

Fig 1. Identification of an inhibitor of Zika NS2B-NS3pro from eatable plants.

(A). Chemical structure of quercetin extensively existing in many fruits and vegetables including Papaya (B). Here we identified quercetin to be an inhibitor of Zika NS2B-NS3pro (C); thus suggesting that fruits and vegetables containing quercetin have anti-Zika activity (D).

Therefore we further determined the $\mathrm{IC}_{50}$ and $K_{\mathrm{i}}$ values of quercetin. Briefly, for determination of $\mathrm{IC}_{50}$, the protease at $50 \mathrm{nM}$ was pre-incubated at $37{ }^{\circ} \mathrm{C}$ for $30 \mathrm{~min}$ with quercetin at various concentrations and the reaction was initiated by adding Bz-nKRR-AMC to $250 \mu \mathrm{M}$. The obtained data (Fig $2 \mathrm{~B}$ ) were fitted to be $26.0 \pm 0.1 \mu \mathrm{M}$ by GraphPad Prism $7.0(20)$

For $K \mathrm{i}$ determination, the assay was performed with different final concentrations of both quercetin and substrate. The protease at $50 \mathrm{nM}$ was pre-incubated with quercetin at different concentrations for $30 \mathrm{~min}$ at $37^{\circ} \mathrm{C}$. Subsequently, the reaction was initiated by addition of the corresponding concentration series of the substrate. The $K \mathrm{i}$ was obtained to be 
$23.0 \pm 1.3 \mu \mathrm{M}$ by fitting the data (Fig $2 \mathrm{C}$ ) in the non-competitive inhibition mode (20). It is interesting to find that quercetin acts as a non-competitive inhibitor for Zika NS2B-NS3pro. This clearly suggests that quercetin is an allosteric inhibitor which binds to the site having no direct overlap with the substrate binding pocket of Zika NS2B-NS3pro. We are currently focused on decoding whether quercetin in fact acts as a dynamically-driven allosteric inhibitor as previously observed on other viral proteins (21-25). Furthermore, we also attempted to utilize NMR spectroscopy to facilitate the optimization of the inhibitors (26-31).
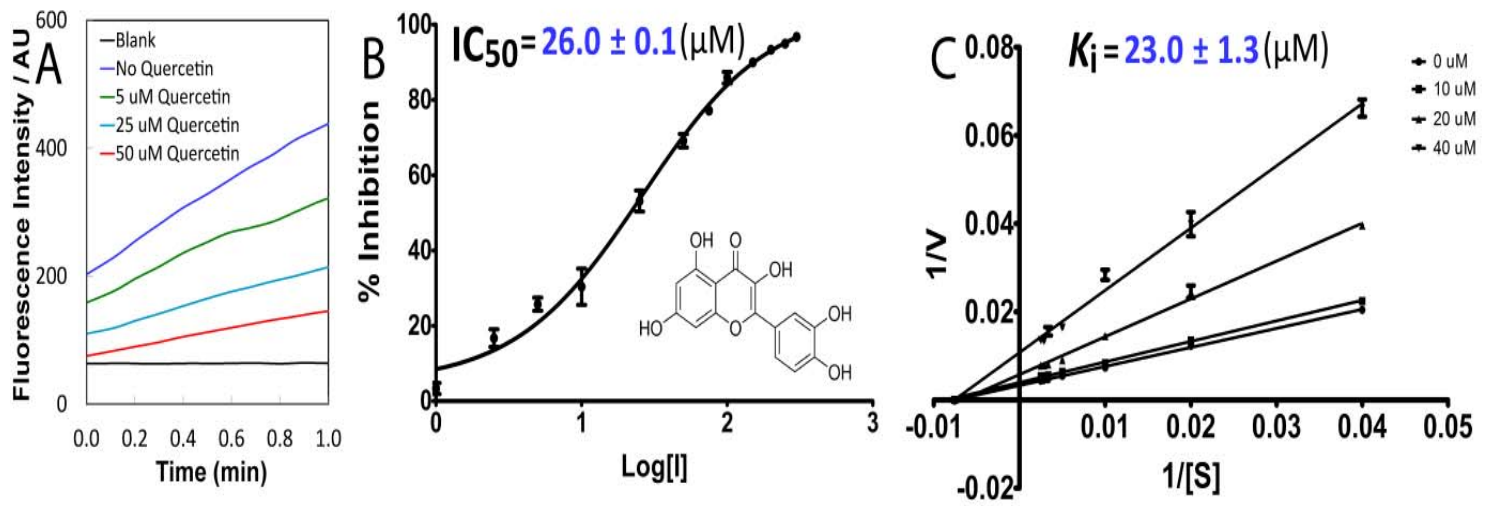

Fig 2. Characterization of inhibitory effects of quercetin.

(A) The tracings of the fluorescence intensity within $1 \mathrm{~min}$ for Zika NS2B-NS3pro in the presence of quercetin at different concentrations. (B) Fitting curve for $\mathrm{IC}_{50}$ of quercetin. (C) The Lineweaver-Burk plot for determing $K_{\mathrm{i}}$ of quercetin. [S] is the substrate concentration; V is the initial reaction rate. Both curves were generated by the program GraphPad Prism 7.0.

Quercetin is a flavonoid extensively found in many fruits, vegetables, leaves and grains, which have been used as an ingredient in supplements, beverages, or foods. It has been previously documented that quercetin has beneficial health effects ranging from antioxidant to nutraceutical (32). Recently it has also been shown that herbal medicines containing quercetin or quercetin-like molecules showed significant antiviral activities on SARS and Dengue viruses (33-35). Here, for the first time, we provide the experimental evidence that quercetin is also an inhibitor of Zika NS2B-NS3pro, which is absolutely essential for cleaving the Zika polyprotein into functional subunits. Therefore, quercetin- 
containing fruits and vegetables can join in to fight Zika virus right away. Moreover, quercetin can also serve as a starting point for further design of inhibitors of high affinity and specificity for fighting Zika. 


\section{Conclusion}

For the first time, our study discloses that quercetin is an inhibitor of Zika NS2B-NS3 protease, which consequently should have capacity in inhibiting Zika replication. In particular, with consideration of the fact that quercetin has been extensively found in many fruits, vegetables, leaves and grains, our discovery would benefit the public to immediately fight Zika. 


\section{References}

1. Dick GW, Kitchen SF, Haddow AJ. Zika virus isolations and serological specificity. Trans R Soc Trop Med Hyg. 1952; 46: 509-20.

2. Wikan N, Smith DR. Zika virus: history of a newly emerging arbovirus. Lancet Infect Dis. 2016; pii: S1473-3099(16)30010-X.

3. Faye O, Freire CC, Iamarino A, Faye O, de Oliveira JV, Diallo M, et al. Molecular evolution of Zika virus during its emergence in the 20th century. PLoS Negl Trop Dis. 2014; 8:e2636.

4. Baronti C, Piorkowski G, Charrel RN, Boubis L, Leparc-Goffart I, de Lamballerie X. Complete coding sequence of zika virus from a French polynesia outbreak in 2013. Genome Announc. 2014; 2(3): pii: e00500-14.

5. Bogoch II, Brady OJ, Kraemer MU, German M, Creatore MI, Brent S, Watts AG, Hay SI, Kulkarni MA, Brownstein JS, Khan K. Potential for Zika virus introduction and transmission in resource-limited countries in Africa and the Asia-Pacific region: a modelling study. Lancet Infect Dis. 2016; S1473-3099(16): 30270-5.

6. Mlakar J, Korva M, Tul N, Popovic M, Poljsak-Prijatelj M, Mraz J, Kolenc M, Resman Rus K, Vesnaver Vipotnik T, Fabjan Vodusek V et al; Zika virus associated with microcephaly. N Engl J Med. 2016; 374:951-958

7. Dejnirattisai W, Supasa P, Wongwiwat W, Rouvinski A, Barba-Spaeth G, Duangchinda T, Sakuntabhai A, Cao-Lormeau VM, Malasit P, Rey FA, Mongkolsapaya J, Screaton GR. Dengue virus sero-cross-reactivity drives antibody-dependent enhancement of infection with zika virus. Nat Immunol. 2016; doi: 10.1038/ni.3515.

8. Li C, Xu D, Ye Q, Hong S, Jiang Y, Liu X, Zhang N, Shi L, Qin CF, Xu Z. Zika Virus Disrupts Neural Progenitor Development and Leads to Microcephaly in Mice. Cell Stem Cell. 2016; ; pii: S1934-5909(16)30084-4. 
9. Vogel G. INFECTIOUS DISEASE. Experts fear Zika's effects may be even worse than thought. Science. 2016; 352(6292):1375-6.

10. WHO. WHO statement on the fi rst meeting of the International Health Regulations (2005) (IHR 2005) Emergency Committee on Zika virus and observed increase in neurological disorders and neonatal malformations. www.who.int/mediacentre/news/statements/2016/1stemergency-committee-zika/en/

11. Cox BD, Stanton RA, Schinazi RF. Predicting Zika virus structural biology: Challenges and opportunities for intervention. Antivir Chem Chemother. 2016; pii: 2040206616653873. 12. Gupta G, Lim L, Song J. NMR and MD Studies Reveal That the Isolated Dengue NS3 Protease Is an Intrinsically Disordered Chymotrypsin Fold Which Absolutely Requests NS2B for Correct Folding and Functional Dynamics. PLoS One. 2015; 10(8):e0134823.

13. Chambers TJ, Hahn CS, Galler R, Rice CM. Flavivirus genome organization, expression, and replication. Annu Rev Microbiol. 1990; 44:649-88.

14. Leung D, Schroder K, White H, Fang NX, Stoermer MJ, Abbenante G, Martin JL, Young PR, Fairlie DP. Activity of recombinant dengue 2 virus NS3 protease in the presence of a truncated NS2B co-factor, small peptide substrates, and inhibitors. J Biol Chem. 2001; 276(49):45762-71.

15. Nall TA1, Chappell KJ, Stoermer MJ, Fang NX, Tyndall JD, Young PR, Fairlie DP. Enzymatic characterization and homology model of a catalytically active recombinant West Nile virus NS3 protease. J Biol Chem. 2004; 279(47):48535-42.

16. Iempridee $\mathrm{T}$, Thongphung $\mathrm{R}$, Angsuthanasombat $\mathrm{C}$, Katzenmeier $\mathrm{G}$. A comparative biochemical analysis of the NS2B(H)-NS3pro protease complex from four dengue virus serotypes. Biochim Biophys Acta. 2008; 1780(7-8):989-94.

17. Li J, Lim SP, Beer D, Patel V, Wen D, Tumanut C, Tully DC, Williams JA, Jiricek J, Priestle JP, Harris JL, Vasudevan SG. Functional profiling of recombinant NS3 proteases 
from all four serotypes of dengue virus using tetrapeptide and octapeptide substrate libraries. J Biol Chem. 2005; 280(31):28766-74.

18. Erbel P, Schiering N, D'Arcy A, Renatus M, Kroemer M, Lim SP, Yin Z, Keller TH, Vasudevan SG, Hommel U. Structural basis for the activation of flaviviral NS3 proteases from dengue and West Nile virus. Nat Struct Mol Biol. 2006; 13(4):372-3.

19. Lim L, Wei Y, Lu Y, Song J. ALS-Causing Mutations Significantly Perturb the SelfAssembly and Interaction with Nucleic Acid of the Intrinsically Disordered Prion-Like Domain of TDP-43. PLoS Biol. 2016; 14(1):e1002338.

20. Harvey Motulsky and Arthur Christopoulos, Fitting Models to Biological Data using Linear and Nonlinear Regression. A Practical Guide to Curve Fitting. , Oxford University Press, New York, 2004. ISBN: 0195171802.

21. Ma B, Nussinov R. Structured crowding and its effects on enzyme catalysis. Top Curr Chem. 2013; 337:123-37.

22. Shi J, Han N, Lim L, Lua S, Sivaraman J, Wang L, Mu Y, Song J. Dynamically-driven inactivation of the catalytic machinery of the SARS 3C-like protease by the N214A mutation on the extra domain. PLoS Comput Biol. 2011; 7(2):e1001084.

23. Lim L, Shi J, Mu Y, Song J. Dynamically-driven enhancement of the catalytic machinery of the SARS 3C-like protease by the S284-T285-I286/A mutations on the extra domain. PLoS One. 2014; 9(7):e101941.

24. Gupta G, Qin H, Song J. Intrinsically unstructured domain 3 of hepatitis C Virus NS5A forms a "fuzzy complex" with VAPB-MSP domain which carries ALS-causing mutations. PLoS One. 2012; 7(6): e39261.

25. Yildiz M, Ghosh S, Bell JA, Sherman W, Hardy JA. Allosteric inhibition of the NS2BNS3 protease from dengue virus. ACS Chem Biol. 2013; 8:2744-52. 
26. Song J, Ni F. NMR for the design of functional mimetics of protein-protein interactions: one key is in the building of bridges. Biochem Cell Biol. 1998; 76(2-3):177-88.

27. Shi J, Wei Z, Song J. Dissection study on the severe acute respiratory syndrome 3C-like protease reveals the critical role of the extra domain in dimerization of the enzyme: defining the extra domain as a new target for design of highly specific protease inhibitors. $\boldsymbol{J}$ Biol Chem. 2004; 279(23): 24765-73.

28. Qin H, Shi J, Noberini R, Pasquale EB, Song J. Crystal structure and NMR binding reveal that two small molecule antagonists target the high affinity ephrin-binding channel of the EphA4 receptor. J Biol Chem. 2008; 283(43): 29473-84.

29. Qin H, Noberini R, Huan X, Shi J, Pasquale EB, Song J. Structural characterization of the EphA4-Ephrin-B2 complex reveals new features enabling Eph-ephrin binding promiscuity. $\boldsymbol{J}$ Biol Chem. 2010; 285(1): 644-54.

30. Petty A, Myshkin E, Qin H, Guo H, Miao H, Tochtrop GP, Hsieh JT, Page P, Liu L, Lindner DJ, Acharya C, MacKerell AD Jr, Ficker E, Song J, Wang B. A small molecule agonist of EphA2 receptor tyrosine kinase inhibits tumor cell migration in vitro and prostate cancer metastasis in vivo. PLoS One. 2012; 7(8):e42120.

31. Qin H, Lim LZ, Song J. Dynamic principle for designing antagonistic/agonistic molecules for EphA4 receptor, the only known ALS modifier. ACS Chem Biol. 2015; 10(2):372-8.

32. Boots AW, Haenen GR, Bast A. Health effects of quercetin: from antioxidant to nutraceutical. Eur J Pharmacol. 2008; 582(2-3): 325-37.

33. Ahmad N, Fazal H, Ayaz M, Abbasi BH, Mohammad I, Fazal L. Dengue fever treatment with Carica papaya leaves extracts. Asian Pac J Trop Biomed. 20111; 4: 330-3.

34. Zandi K, Teoh BT, Sam SS, Wong PF, Mustafa MR, Abubakar S. Antiviral activity of four types of bioflavonoid against dengue virus type-2. Virol J. 20118; 560: doi: $10.1186 / 1743-422 X-8-560$. 
35. Chiow KH, Phoon MC, Putti T, Tan BK, Chow VT. Evaluation of antiviral activities of Houttuynia cordata Thunb. extract, quercetin, quercetrin and cinanserin on murine coronavirus and dengue virus infection. Asian Pac J Trop Med. 2016; 9(1): 1-7. 


\section{Acknowledgement}

This study is supported by Ministry of Education of Singapore (MOE) Tier 3 Grant R154-002-580-112; Tier 2 Grant MOE2015-T2-1-111 and National Research Foundation of Singapore (NRF) R-154-002-529-281 to Jianxing Song. The funders had no role in study design, data collection and analysis, decision to publish, or preparation of the manuscript.

\section{Author Contributions}

Conceived the idea: JXS; Performed the experiments: AR LZL; Prepare figures and wrote the paper: JXS. 